\title{
A simple stimulus generator for evoked response studies
}

\author{
JOHN ERDREICH \\ Department of Otorhinolaryngology, Health Sciences Center, The University of Oklahoma \\ P.O. Box 26901, Oklahoma City, Oklahoma 73190
}

\begin{abstract}
An inexpensive computer-driven bipolar stimulator is described. The device produces variable-duration bipolar click stimuli for use in auditory evoked response studies, but is applicable to other research. The unit is driven directly from the digital input/output interface of the averaging computer, and temporal parameters are completely controlled by the machine.
\end{abstract}

When recording auditory evoked responses, it is often desirable to alternate stimulus polarity so that initial cochlear microphonic activity is averaged to zero in the final response. We required a simple bipolar click generator for a dedicated clinical average response system using a Data General NOVA 2/10 computer. Hardware and software simplicity were of more importance than was efficient CPU utilization. For this reason, it was decided to bypass the computer interrupt structure and allow the machine to generate the click stimuli synchronously.

The simplest solution was to define 1 bit of the digital input/output $(\mathrm{I} / \mathrm{O})$ word as a positive pulse and another as a negative pulse. The duration for which one or the other bit was ON determined the pulse width and polarity of the output. The time for which both bits were OFF determined the interstimulus interval.

\section{Circuit Description}

The click generator consists of three sections (Figure 1). The first (ICI) is a differential input amplifier (Motorola MC 1439). With Bit B ON, the output is positive; Bit $A$ ON produces a negative output of equal amplitude. The second section (IC2, MC 1439) is an active low-pass filter with a cutoff frequency of about
$9 \mathrm{kHz}$. This aids in minimizing acoustic transients produced by the short rise time of the electrical pulse. The amplifier section (IC3, Motorola MC 1433) following the filter allows loads as low as $30 \mathrm{ohms}$ to be driven. In addition, the input circuitry at Pin 4 may be modified to allow the addition of other signals to be stimulus waveform. The decade attenuator (AT) was incorporated into the device for stimulus amplitude control.

Table 1

Parts List

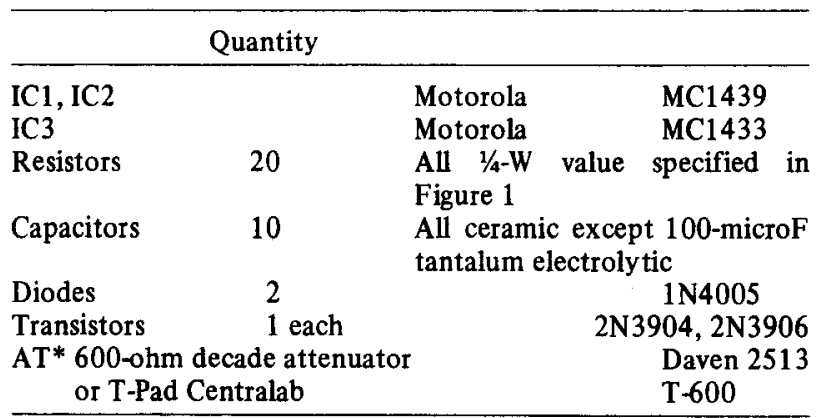

*All items except the Daven attenuator are available through local electronic parts distributors. Address for Daven is Edison Electronics, Grenier Field Municipal Airport, Manchester, New Hampshire 03103.

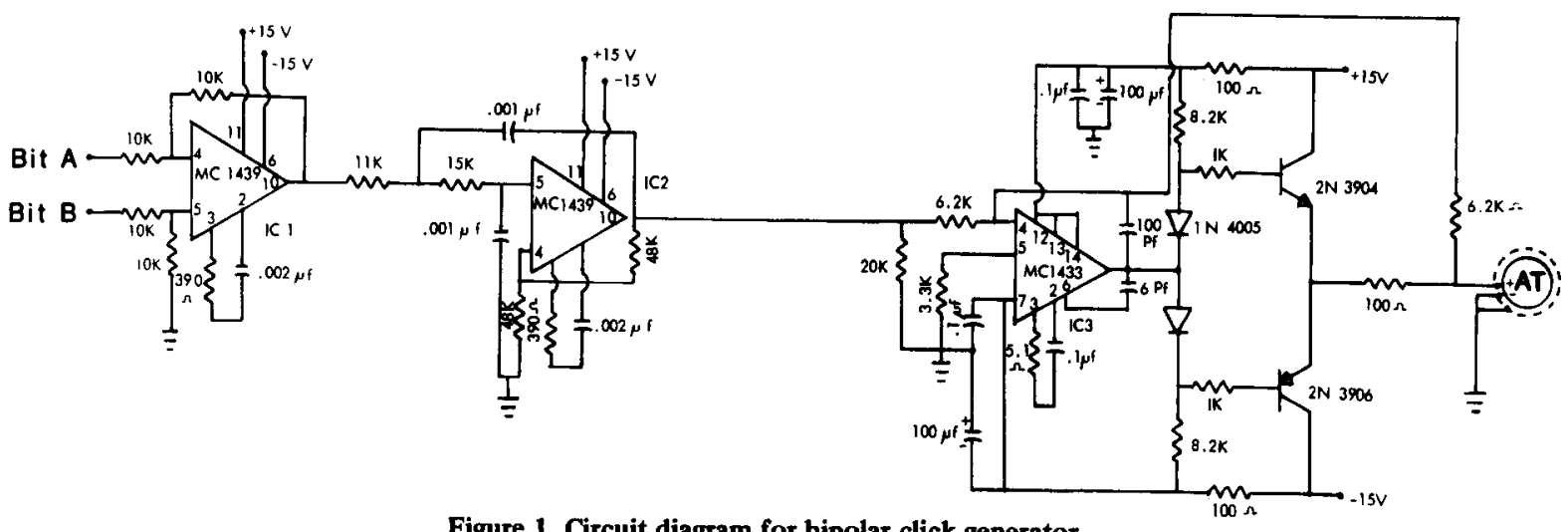

Figure 1. Circuit diagram for bipolar click generator. 
With the exception of the attenuator and the power supply that we built into the unit, cost of parts is trivial; suitable voltage sources $( \pm 15 \mathrm{~V})$ already exist in most laboratories. An inexpensive T-pad attenuator can be substituted for the decade attenuator in this design, further minimizing cost. A parts list is provided in Table 1.

(Received for publication August 26, 1977; revision accepted October 4,1977 .) 